\title{
Experimental Study of CLARK-Y Smoothed Inverted Wing with Ground Effect
}

\author{
Ihsan Y. Hussain, PhD \\ Mech. Engr. Dept. \\ University of Baghdad \\ Iraq-Baghdad
}

\author{
Mustafa S. Abood \\ Mech. Engr. Dept. \\ University of Baghdad \\ Iraq-Baghdad
}

\begin{abstract}
Aerodynamic characteristics of inverted single element airfoil with and without ground effect had been investigated experimentally in Low-Speed Wind Tunnel of test cross section area $\left(0.7 \times 0.7 \mathrm{~m}^{2}\right)$ and maximum velocity $55 \mathrm{~m} / \mathrm{s}$ to quantify the aerodynamic characteristics of inverted CLARK-Y smoothed airfoil. The ground effect was introduced by using a fixed flat board moves vertically to produce the required distance between the airfoil and ground board. The model was tested with and without ground effect and at various wind tunnel velocities (Reynolds numbers), ride heights (ground clearances) and angles of attack. Data obtained in airfoil experiments include sectional forces and surface pressure data. Results are compared with the free-drive case and with published works. Data indicated that the pressure distribution increased at the upper and lower surfaces in ground proximity, at low angles of attack, and increased also with incidence. The negative lift coefficient increased with angle of attack except the angles of attack larger than $10^{\circ}$ and with ground effects except at ride heights of less than $0.1 \mathrm{c}$ due to the force reduction phenomena. The drag coefficient increased with the ground effect which caused a decrease in the airfoil efficiency. The aerodynamic characteristics remain relatively an affected by the velocity change. The experimental data were compared with published works and showed good results.
\end{abstract}

\section{Keywords}

Inverted Wing, Ground Effect, Free-Drive, Experimental Study, Aerodynamic Characteristics, CLARK-Y smoothed (clarkysm-il) Airfoil.

\section{INTRODUCTION}

An inverted airfoil in ground effect can be considered a very simplified representation of the front wing of a racing car. The aerodynamics of the front wing is very important since it contributes for about $30 \%$ to the total down-force of the car, and because the air that flows over and under the front wing enters the under tray, influencing the underbody flow. Of basic importance is, in particular, the understanding of the relation between down-force generated and clearance between the ground and the airfoil. For an inverted wing, the effect of decreasing the ride height is similar to increasing the angle of attack (AOA) of a regular airfoil: as for a regular airfoil, the lift increases with the angle of attack until a maximum is reached and the wing stalls; the down-force generated by an inverted wing in ground effect, increases as the ride height is reduced up to a critical point after which the down-force drops [1].

The inverted wing when located within close proximity to a ground plane, the flow field generated by an inverted wing increases in complexity when compared to the free stream case. In free airflow stream single-element airfoils induce a flow field controlled by the effects of viscosity including regions of highly curved streamlines, merging wakes, and confluent boundary layers. The combination of flow field of a single- element airfoil and a ground effect situation will generate a mostly viscous flow field, interactive and highly complex [2] and [3]

Previous studies conducted on the inverted wings with the effect of the ground have illustrated the advantage in terms of negative lift, down-force, which may be attained, for example Dominy [4] and Katz [5] showed experimentally a sample of pressure distributions at distances of 0.3 of the chord length (c) between the ground plane and lowest point on the suction surface, generating more down-force in compression with the free-stream situation. Among various studies, Knowles et al. [6] were the first to investigate experimentally and computationally a singleelement wing with the suction surface close to a moving ground. They performed an experimental investigation on a single element GA(W)-1 airfoil that represents the front inverted wing of a race car using rolling road facility. The sectional force results and a sample of surface pressure distributions for different angles of attack at ride heights varying from $0.12 \mathrm{c}$ up were given, but their studies are still leaving gaps in the understanding of the topic, because of the limited number of ground clearances falling to include the force reduction phenomenon. They documented that at specific angle of attack, operating in low ride heights, gives increased values of down-force compared with freestream situation. Jasinski and Selig [7] experimentally investigated an inverted double element open wheel race car front wing tested in and out of ground effect and at various speeds, angles of attack and flap positons. The main element and flap were specifically designed for the investigation based on the UIUC700 two element airfoil and were mounted in a single slotted configuration. The ground was stationary and impermeable during all investigations producing an unrealistic ground boundary layer. They tested both a two-dimensional wing and a three-dimensional wing with endplates. No data was presented for the two-dimensional wing. Down-force results were presented for various flap incidences and freestream velocities $\left(\mathrm{Re}=0.7 \times 10^{6}\right.$ to $\left.1.3 \times 10^{6}\right)$ for a fixed ride height $(\mathrm{h} / \mathrm{c})$ of 0.3 of the chord. They showed that the elementary factors in the design of race car front airfoil have a significant effect on wing performance and behavior of the down-stream flow field. Zerihan and Zhang [8] investigated the aerodynamic characteristics of an inverted airfoil in the effect of the ground using model experiments in low speed $2.1 \mathrm{~m} \times 1.7 \mathrm{~m}$ wind tunnel supplied with moving ground. The wind and ground 
velocities were set at $30 \mathrm{~m} / \mathrm{s}$ for the majority of experiments, corresponding to a Reynold number of nearly $2.0 \times 10^{6} / \mathrm{m}$. So they made the test runs with $30 \mathrm{~m} / \mathrm{s}$ and 20 $\mathrm{m} / \mathrm{s}$ velocities. The wing profile was the main element front wing of the Tyrrel 026 Formula one car. They developed the airfoil from modifications to NASA GA (W) profile isolated wing, by making the suction surface closer to the ground, to study the effect of varying both the angle of attack, and the ride height from the ground. The angle of attack was varied using rotation so the angles of attack from $-10^{\circ}$ to $25^{\circ}$. The extracted results in the model simulations contained surface pressure results, force balance measurements and surface oil flow visualization. These results were compared with the free stream situation. They concluded that as the ground clearance was reduced, the down-force was increased; at ride heights of less than $0.2 \mathrm{c}$, the down-force is significantly higher. In very close ground proximity, $\mathrm{h} / \mathrm{c}$ less than 0.1 , the wing stalls and down-force decreases. They observed the force reduction phenomena which caused by the boundary layer separation near the trailing edge. Galoul and Barber [9] investigated experimentally the aerodynamics of an inverted airfoil with endplates in the effect of the ground. The airfoil used was the NACA 4412 section. All the tests were operated with an inlet velocity of $10.5 \mathrm{~m} / \mathrm{s}$ that it is corresponding to the Reynolds number of about 50,000 based on the chord length. A wind tunnel has $228 \mathrm{~mm}$ width, $485 \mathrm{~mm}$ height and equipped with a moving belt and the measurements were done using LDA. Firstly, they studied the size effect of the endplate and the ride height on the vortices behavior. Then, they studied the most relevant designs of the airfoils using LDA measurements. Walter [10] investigated the effect of ride height on the coefficients of lift, drag and moment for, 2-D airfoils. The aim of his investigation was to study the effect of the ride height on airfoils post stall, so as to increase the performance of a race car. He used the models Clark Y, 6-series (63-412) and a modified 6-series (63-412 with Gurney Tab). The airfoils were experimented at incidences ranging from $0^{\circ}$ to $135^{\circ}$. The used Reynolds number was $2.16 \times 10^{5}$ based on chord length for all tests. $\mathrm{He}$ calculated forces by using pressure taps along the center line of the airfoil. A delay in the stall of the wing tested with reduced ride height was seen in the results. Two of the tested airfoils showed a decrease in lift coefficient with decreasing ride height; the third showed an increase. The drag coefficient of the airfoil post-stall decreased with reduced ride height. A different study by Blackwell [11] that he used Clark-y smoothed airfoil as a model in wind tunnel for finding 2-D and 3-D flows corrections due to the effects of the walls of the wind tunnel and another flow phenomenon. He developed the corrections from the buoyance, wake and solid blockage and the curvature corrections of the streamline. He investigated the aerodynamic characteristics theoretically and experimentally with its corrections at free flight case and wind tunnel inlet velocities of $6,30,68$ and $102 \mathrm{mph}$ for angles of attack varied form $-4^{\circ}$ to $16^{\circ}$.

In the current investigation, a single element inverted airfoil in ground effect is investigated experimentally. The airfoil used is CLARK-Y smoothed type. The free stream velocity is variant $25,30,35$ and $40 \mathrm{~m} / \mathrm{s}$, corresponding to an incompressible airfoil chord length Reynolds numbers of $4.96 \times 10^{5}, \quad 5.96 \times 10^{5}, \quad 6.95 \times 10^{5}$ and $7.94 \times 10^{5}$, respectively and the ride height $(\mathrm{h} / \mathrm{c})$ also changed from 0.05 to 0.2 for different incidences from zero to $15^{\circ}$. The focus of this investigation is on both pressures surface and the sectional forces flow field, since practice dictates that other aerodynamic components follow the front wing of a racing car.

\section{EXPERIMENTAL APPARATUS 2.1 The Low-Speed Wind Tunnel}

The experiments were performed in the University of Baghdad low speed $0.7 \times 0.7 \mathrm{~m}^{2}$ wind tunnel to obtain sectional forces and pressure data. The tunnel is open circuit type with a contraction ratio of 9:1 and test section dimensions of $0.7 \mathrm{~m} \times 0.7 \mathrm{~m} \times 1.5 \mathrm{~m}$. The tunnel's fan type is axial flow fan operated by $75 \mathrm{hp}, 3000 \mathrm{rpm}$ AC motor. The maximum calibrated velocity at the center of the test section is $55 \mathrm{~m} / \mathrm{s}$, corresponding to a Reynolds number of about $3.8 \times 10^{6} / \mathrm{m}$ as presented in [12].

\subsection{Model}

Experiments were performed on a single element airfoil shown in (Figure 1). The model was manufactured of (35) wood sections, which are cut precisely using CNC machine. These sections were collected together using PVA adhesive. After smoothing and refining the surface it was painted to be as required, see Figure 2. It can be seen in Figure 1 that positive lift indicates a down-force directed to the ground. $\mathrm{C}_{\mathrm{L}}$ termed in the paper is the downforce or negative lift coefficient and the incidence (angle of attack) is positive when the leading edge of the model is rotated down. The airfoil configuration is CLARK-Y Smoothed (clarkysm-il). The airfoil chord length, c, is $300 \mathrm{~mm}$. The span length of the airfoil is $700 \mathrm{~mm}$ without endplates which represents the test section width to prevent the tip vortices or trailing vortices. The pressure orifices are located along the model with (23) taps on the airfoil surface along the centerline of the span,14 taps on the inverted upper surface and 9 taps on the lower one. The orifices diameter is $1 \mathrm{~mm}$ which is connected with plastic tube of $5 \mathrm{~mm}$ diameter. These tubes are extended to pressure taps selector, which is connected to the MicroManometer to measure the static pressure along the airfoil surface. The pressure taps positions for the airfoil is same as that in. [10].

\subsection{Ground Board}

In the tests, a flat smoothed board was used inside the tunnel test section which is vertically moved up and down to reach the needed ride height. Board height is controlled by loosening and tightening nut and bolt handle placed on the side of the steel structure that supports the board in the test section. The length of the plate was $600 \mathrm{~mm}$ with curved front and it was as wide as the tunnel test section to ensure no tips flow leakage happen in the span-wise direction. The needed ride height is obtained by adjusting the length of the rod supporting the board at leading and trailing edge of the board with help of the bolt placed on the side of the steel structure support the board in the test section. 


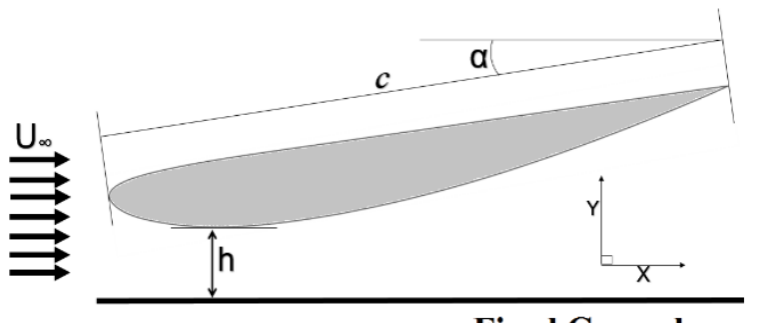

Fixed Ground

Fig 1: Sketch of the Clarkysm-il airfoil near the ground board, showing the definition of airfoil chord $c$, ride height $h$, angle of attack $\alpha$, and freestream velocity $U_{\infty}$.

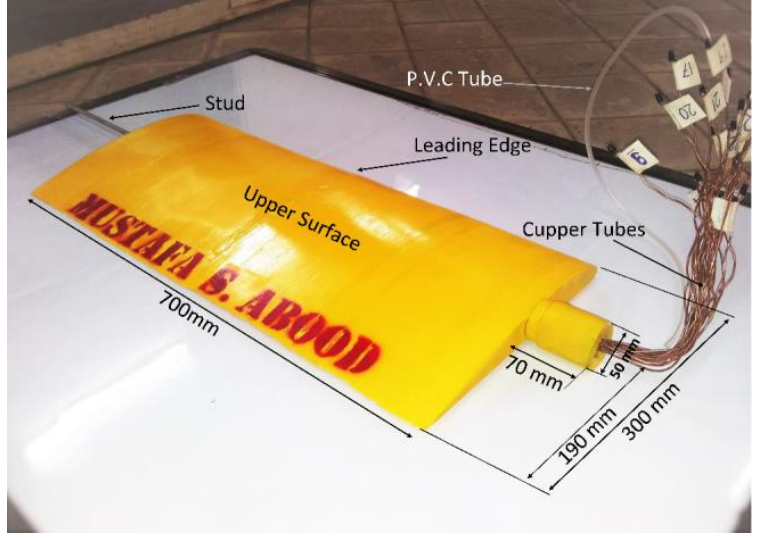

Fig 2: Single Element Airfoil Test Model Used in Wind Tunnel

\section{EXPERIMENTAL PROCEDURES}

After preparing the laboratory for the experiments by opening the doors and windows to the atmosphere and fixing the model inside the tunnel test section. Also, the ground board is fixed and adjusted with specified ride height under the model at the mid of the test section.

The P.V.C tubes were used to connect between the measuring tubes, selector and micro-manometer. The model is rotated and fixed at a specific angle of attack (e.g. $\alpha=0^{\circ}$ ) which is made by the model chord center line parallel to the tunnel roof and considered the reference. Then adjust the ground board at a specific level (e.g. h/c= 0.05) from the lowest point on the lower surface of the airfoil. After that the wind tunnel test section speed is adjusted to a specific value (e.g. $25 \mathrm{~m} / \mathrm{s}$ ). The total pressure and static pressure of the inlet flow are measured by using the Pitot-static tube, which is fixed at the center of inlet plane of the test section. Finally measure the static pressure on the upper and lower surfaces of the model. New test begins with change the test section velocity to $(30,35$ and 40$) \mathrm{m} / \mathrm{s}$ and change the ground plate with newer clearances $(\mathrm{h} / \mathrm{c}=0.1,0.15$ and 0.2$)$. Also, change the model angle of attack $\left(\alpha=5^{\circ}, 10^{\circ}\right.$ and $\left.15^{\circ}\right)$.

Lift and drag data were acquired with integrating the pressure and frictional forces. For each airfoil component the contributions of pressure and wall shear stress are calculated as follows [13];

$$
\begin{aligned}
c_{a}=\frac{1}{c_{r e f}}\left[\int _ { 0 } ^ { c } \left(c_{p_{u}}\right.\right. & \left.\frac{d y_{u}}{d x}-c_{p_{l}} \frac{d y_{l}}{d x}\right) d x \\
& \left.+\int_{0}^{c}\left(c_{f_{u}}+c_{f_{l}}\right) d x\right] \\
c_{n}=\frac{1}{c_{r e f}}\left[\int _ { 0 } ^ { c } \left(c_{p_{l}}\right.\right. & \left.-c_{p_{u}}\right) d x \\
& +\int_{0}^{c}\left(c_{f_{u}} \frac{d y_{u}}{d x}\right. \\
& \left.\left.+c_{f_{l}} \frac{d y_{l}}{d x}\right) d x\right]
\end{aligned}
$$

where subscripts $u$ and $l$ represent the upper and lower surface respectively. $\mathrm{C}_{\mathrm{p}}$ is the pressure coefficient;

$c_{p}=\frac{p_{s}-p_{\infty}}{q_{\infty}}$

and wall shear stress coefficient is;

$c_{f}=\frac{\tau_{w}}{q_{\infty}}$

where $q_{\infty}$

The negative lift coefficient could be calculated from;

$c_{l}=c_{n} \cos (\alpha)-c_{a} \sin (\alpha)$

After converting the pressure data obtained from the experiments into coefficients of pressure. The shear stress is very small in the y-component calculation, because of the small airfoil thickness also in the turbulent boundary layer, so it is neglected in the previous equations, (3.1) \& (3.2) due to its small effect in the down-force calculations and the drag coefficient could be calculated from;

$c_{d}=c_{n} \sin (\alpha)+c_{a} \cos (\alpha)$

The obtained lift and drag data is corrected due to the effect of the three main wall corrections for an airfoil; buoyancy correction, wake blockage and solid blockage detailed in [12], see Table 1 for the integrated force coefficients and their corrections.

\section{RESULTS AND DISCUSSION}

In this section, the effect of ride height, angle of attack and velocity on the aerodynamic characteristics are analyzed, followed by an investigation into the flow physics responsible for this trends by using results of surface chord-wise pressures distribution. Generally, all the results are presented in three levels (maximum, medium and minimum levels). Each parameter will be presented at three different values of the other variables, which represent the highest, middle and lowest values. For example: when studying the effect of ride height on the negative lift coefficient, the results are represented in three levels. Maximum level is at $\mathrm{v}=40 \mathrm{~m} / \mathrm{s}, \alpha=15^{\circ}$ and $\mathrm{h} / \mathrm{c}=$ 0.2 . Medium level is at $\mathrm{v}=30 \mathrm{~m} / \mathrm{s}, \alpha=5^{\circ}$ and $\mathrm{h} / \mathrm{c}=0.1$ and Minimum level is at $\mathrm{v}=25 \mathrm{~m} / \mathrm{s}, \alpha=0^{\circ}$ and $\mathrm{h} / \mathrm{c}=0.05$.

\subsection{Sectional Forces Analysis}

\subsubsection{Effect of Ride Height}

The down-force (negative lift) and drag coefficients variations with angle of attack for set of studied ride heights, including the free-drive case, at different speeds $(25,30,35$ and $40 \mathrm{~m} / \mathrm{s})$ are given in Figures $3(\mathrm{a}, \mathrm{b}, \mathrm{c}$ and d). The free-drive (free of ground) case also presented 
with ride height variations of ground effect case for comparison. With the airfoil in proximity to the ground, the effect of higher down-force coefficients can be seen clearly. The physical effects of the ground are to constrain the airflow over the suction surface of the airfoil. This causes an acceleration of the flow, if compared with the case out of ground effect and results in a greater suction on the suction surface, and hence a higher down-force. As the ride height is reduced, the ground effect causes the flow to be accelerated to a higher degree, generating a significantly higher down-force, as can be seen in figure 3 . At ride height of $0.1 \mathrm{c}$ and lesser, there is a gradual, and then significant deviation from the previous trend of ever increasing down-force with reduction in ride height. Closer to the ground than this point, the down-force reduces significantly compared with the maximum (the force reduction phenomenon). The maximum down-force occurs at the same height of $0.2 \mathrm{c}$. Also, in the Figure 3 the effect of ride height on the drag of the wing is shown. It has been shown that as the ride height is reduced, the down-force increases until the beginning of the force reduction phenomenon for low angles of attack. This contributes to the induced drag of the wing. As boundary layer separation occurs at heights above the force reduction height, downwards this also contributes to the drag. These two factors are the reasons for the drag of the wing increasing with reducing the ride height. As the proximity to the ground is increased, the drag force increases. From the figures can be concluded that the free-drive case is the lesser drag and down-force comparing with the ground effect case.

Figure 4 shows the negative lift to drag (efficiency) variation with angle of attach for a set of studied ride heights, including the free-drive case, at four reference speeds (a to d). As the ride height increases as the efficiency increases, so the maximum efficiency is for free -drive case and at $\mathrm{h} / \mathrm{c}=0.2$ for ground effect case.

\subsubsection{Effect of the Angle of Attack}

In Figure 3, the effect of the incidence is very clear on the lift and drag. For the lowest ride heights at the $\mathrm{h} / \mathrm{c}=0.05$ the force reduction phenomena can be seen after $15^{\circ}$ angle of attack for the four velocities cases, Figures 3 (a) to (d). Of note is the trend of the post-stall (boundary layer separation) curves, similar in shape, showing slightly decreasing down-force coefficient with increasing angle of attack. As for the free-drive case the $\mathrm{C}_{\mathrm{L}}$ curves tend to be constant after the $\alpha=10^{\circ}$ (the separation regions). The drag coefficient for all velocity cases follows the same general trend. As the angle of attach increased as the drag increased for all ride heights cases.

The effect of incidence variation on the lift to drag coefficient $\left(C_{L} / C_{D}\right)$ for four speeds is presented in the Figure 4. As the angle of attack increases the $C_{L} / C_{D}$ decreases, only for ride heights less than 0.15 , and increases with increasing the angle of attack for $h / c$ larger than 0.15 including the free-drive case till the $\alpha=5^{\circ}$, which at there the maximum value of efficiency for all cases, then return to decrease.

\subsubsection{Effect of Flow Velocity}

Figure 3 (a to d) shows the effect of velocity on downforce curves and drag coefficient for the CLARK-Y smoothed (clarkysm-il) configuration. As velocity or Reynolds number increases, lift coefficient slightly increases and drag coefficient slightly decrease for the tested values of velocities. Typical increases in negative lift coefficient for an increase in velocity from $25 \mathrm{~m} / \mathrm{s}$ to 30 $\mathrm{m} / \mathrm{s}$ averaged $7.5 \%$, while an increase in velocity from 30 $\mathrm{m} / \mathrm{s}$ to $35 \mathrm{~m} / \mathrm{s}$ caused an average increase in $C_{L}$ of $1.2 \%$, whereas the average increase in $\mathrm{C}_{\mathrm{L}}$ is $0.54 \%$ for velocity increasing from $35 \mathrm{~m} / \mathrm{s}$ to $40 \mathrm{~m} / \mathrm{s}$. Generally, from the figures 3 ( $a$ to $d$ ) they are similar in behavior where the values of $\mathrm{C}_{\mathrm{L}}$ not much vary with velocity change for the used values also for the $C_{D}$ trends they are not much differing from the $\mathrm{C}_{\mathrm{L}}$ trends but inversely proportional to the velocity and angle of attack. In comparison with free of ground effect case, the velocity under the airfoil is less than the case of ground effect because the large area of the converging and diverging passage compared with case of ground effect, so the velocity difference between the minimum and maximum value increases with decreasing the ride height. The velocity effect appears clearly in the lift to drag ratio, see Figure 4. As the velocity increases the lift to drag ration increases also.

\subsection{Surface Pressures Distribution}

\subsubsection{Effect of Ride Height}

To investigate the effects of ride height variation, calculations were performed at $\mathrm{h} / \mathrm{c}=\infty, 0.05,0.1$ and 0.2 and data concerning the surface pressures was extracted. The calculated surface pressures are presented in Figure 5. Figures 5(a), (b) and (c) present the surface pressures for different ride heights including the free- drive case at $\alpha=0^{\circ}$ and $\mathrm{v}=25 \mathrm{~m} / \mathrm{s}, \alpha=5^{\circ}$ and $\mathrm{v}=30 \mathrm{~m} / \mathrm{s}$ and $\alpha=15^{\circ}$ and $\mathrm{v}=40$ $\mathrm{m} / \mathrm{s}$, respectively. As the ride height is reduced, the spike (suction peak) on the suction surface increases. In close proximity to the ground, regions of flow separation can be seen at the trailing edge, represented by the constant pressure region, initially small, but increasing in size with reducing the ride height. The stream-wise location of stagnation on the wing and the spike were found to move upstream with reducing ride height. The upper pressure surface on the inverted wing shows small increment with ride height, when compared to the suction surface pressures, and were accurately predicted for all ride heights, but for the free-drive case the upper surface pressure shows a clear difference with ground effect cases. Also, it can be seen the clear difference in the lower suction surface size between the free-drive case and the ground effects cases, whereas the vacuum region on the suction surface slightly decreases in size with increasing ride height but the free-drive case shows a large difference in the suction region size comparing with the rest cases of ground effects, see figures 5 (a) \& (b). Figure 5(c) shows that the surface pressures trends are identical in behavior for three ride heights and the free-drive cases and shows a little difference in lower and upper surface pressure between all the studied heights including the free drive case. The flow separation started earlier with decreasing the ride height.

\subsubsection{Effect of Angle of Attack}

The effect of angle of attack variation is investigated. Calculations were performed at $\alpha=0,10$ and $15^{\circ}$ to extract data about surface pressures and suctions. The calculated surfaces pressures data are presented in figure 6. Figures $6(\mathrm{a}, \mathrm{b}$ and $\mathrm{c})$ present the surface pressure for three cases, in the first case $\mathrm{h} / \mathrm{c}=0.05$ and $\mathrm{v}=25 \mathrm{~m} / \mathrm{s}$ and in the second case $\mathrm{h} / \mathrm{c}=0.1$ and $\mathrm{v}=30 \mathrm{~m} / \mathrm{s}$ in the third case $\mathrm{h} / \mathrm{c}=0.2$ and $\mathrm{v}=40$ $\mathrm{m} / \mathrm{s}$, using the same previous procedure. As the angle of attack is reduced, the spike on the suction surface decreases and moves upstream. At the zero angle of 
attack the pressure curve is different from the another two investigated angles, where the most pressure coefficients values are negative and the point after the peak directly drops to the negative side. In higher angles of attack regions of flow separation can be seen at trailing edge for all three cases initially small for $\alpha=0$, but being more clear and earlier to happen with increasing the angle of attack. The surface pressure on the pressure side of the wing increases with increasing angle of attack for all three cases.

\subsubsection{Effect of Flow Velocity}

The variation of velocity and its effect on the surface pressure is shown in figure 7 . The tests were performed at $\mathrm{v}=25,30$ and $40 \mathrm{~m} / \mathrm{s}$ at reference values of ride height and angle of attack. The three figures $7(a$ and $b$ ) indicate the two cases of varying the references for different velocities in each case. From the figures it can be seen that the surface pressures, suction peak and separation of fluid flow remain relatively independent of velocity, when the three curves are approximately identical. Whereas the suction region of lower surface of the wing slightly decreases with increasing the velocity for the two cases.

\subsection{Verification of the Results}

A comparison between the present and the previous theoretical and experimental works had been made for the pressure distribution and the lift coefficient for clarkysm-il airfoil in free of ground and with ground effect.

Concerning clarkysm-il airfoil, there is few experimental published papers or researches investigating the inverted Clark-Y smoothed airfoil aerodynamic characteristics with ground effect, where some of them studied different types of airfoils not clarckysm-il and others studied the same airfoil of this study but not inverted or without ground effect. For these reasons there are little published papers used to verify the experimental work with minor differences, these are Hussian and Abood [14], Riegels [15], Lyon et al. [16], Walter [10] and Blackwell [11]. The first published paper indicates the theoretical investigation using COMSOL 5.0 software for the same airfoil and conditions of this work, whereas some of these works presented a straight airfoil surface pressure distribution and others presented lift and drag coefficients, see figure 8 . Figure 8 shows that the theoretical pressure distribution along the airfoil surfaces are in good agreement with the wind tunnel experimental results especially at the upper surface due to the flatness of the upper surface, which makes the errors limited for pressure distribution with chord-wise. The suction surface indicates some difference between the theoretical and the experimental data due to many reasons; the main one is the manufacturing problems, like the surface smoothing and the capillary tubes blockages, the second reason is the model vibration especially at high speeds which makes the pressure measuring inaccurate, also the ground board effects on the lower surface of the model compared with theoretical procedure of ground simulation and there are many minor reasons like the laboratory conditions, wind tunnel walls effect and others. Figure 9 shows the aerodynamic characteristics comparison between the theoretical results, in [14], and the experimental results, with ground effect. The theoretical aerodynamic characteristics are in a good agreement and very close to the wind tunnel experimental results. Figure 10(a) shows comparison between the published papers, Riegels [15] and Walter [10], and the present data for surface pressure distribution of the clarkysm-il at angle of attack of $10^{\circ}$ and $\mathrm{Re}=710000$ without ground effect to verify the methods of solution of problem. The surface pressure is in good agreement with the published experimental work except at the leading edge, which shows a slightly increase in the suction pressure due to the difference in the upper and lower surfaces positions of the airfoil of the present work than the published works. The lift coefficient for free drive case is shown in figure 10(b), despite of; small disagreement between theoretical and experimental data at high angles of attack, the stalling angle and the overall trend of the lift coefficient are in good agreement with Blackwell [11] and Lyon et al. [16] works. This small disagreement maybe due to the velocity difference between this work and the compared works. Poor agreement between theoretical and experimental work are indicated for the lift coefficient with ground effect, Figure 10 (c), and the drag coefficient with ground effect, Figure 10 (d), due to the difference in the way of computing the force coefficients between the present study and the Walter's [10] study.

Table 1. Aerodynamic characteristics results and their corrections

\begin{tabular}{|c|c|c|c|c|c|c|c|}
\hline $\begin{array}{c}\text { Ride } \\
\text { Height } \\
\text { (h/c) }\end{array}$ & $\begin{array}{c}\text { Velocity } \\
(\mathrm{m} / \mathrm{s})\end{array}$ & $\begin{array}{l}\text { AoA } \\
\text { Deg. }\end{array}$ & $\mathrm{C}_{\mathrm{L}}$ & $C_{D}$ & $\begin{array}{c}\text { Corrected } \\
\mathrm{C}_{\mathrm{L}}\end{array}$ & $\begin{array}{c}\text { Corrected } \\
C_{D}\end{array}$ & $C_{L} / C_{D}$ \\
\hline \multirow{16}{*}{0.05} & \multirow{4}{*}{25} & 0 & 0.810 & 0.045 & 0.760 & 0.043 & 17.547 \\
\hline & & 5 & 1.247 & 0.078 & 1.170 & 0.075 & 15.596 \\
\hline & & 10 & 1.425 & 0.133 & 1.337 & 0.129 & 10.369 \\
\hline & & 15 & 1.439 & 0.217 & 1.349 & 0.210 & 6.421 \\
\hline & \multirow{4}{*}{30} & 0 & 1.017 & 0.050 & 0.954 & 0.048 & 19.863 \\
\hline & & 5 & 1.395 & 0.080 & 1.309 & 0.077 & 16.958 \\
\hline & & 10 & 1.552 & 0.139 & 1.456 & 0.134 & 10.844 \\
\hline & & 15 & 1.537 & 0.224 & 1.441 & 0.217 & \begin{tabular}{|l|}
6.652 \\
\end{tabular} \\
\hline & \multirow{4}{*}{35} & 0 & 1.079 & 0.049 & 1.012 & 0.047 & 21.489 \\
\hline & & 5 & 1.445 & 0.079 & 1.355 & 0.076 & 17.786 \\
\hline & & 10 & 1.594 & 0.138 & 1.495 & 0.134 & 11.188 \\
\hline & & 15 & 1.581 & 0.225 & 1.483 & 0.217 & 6.833 \\
\hline & \multirow{4}{*}{40} & 0 & 1.126 & 0.048 & 1.056 & 0.046 & 22.924 \\
\hline & & 5 & 1.477 & 0.078 & 1.385 & 0.075 & 18.423 \\
\hline & & 10 & 1.624 & 0.137 & 1.524 & 0.132 & 11.506 \\
\hline & & 15 & 1.604 & 0.223 & 1.504 & 0.216 & 6.976 \\
\hline \multirow{16}{*}{0.1} & \multirow{4}{*}{25} & 0 & 0.900 & 0.032 & 0.844 & 0.031 & 27.341 \\
\hline & & 5 & 1.412 & 0.060 & 1.324 & 0.058 & 22.895 \\
\hline & & 10 & 1.523 & 0.114 & 1.428 & 0.110 & 12.944 \\
\hline & & 15 & 1.543 & 0.197 & 1.447 & 0.191 & \begin{tabular}{|l|}
7.591 \\
\end{tabular} \\
\hline & \multirow{4}{*}{30} & 0 & 1.066 & 0.034 & 1.000 & 0.033 & 30.285 \\
\hline & & 5 & 1.530 & 0.060 & 1.435 & 0.058 & 24.674 \\
\hline & & 10 & 1.654 & 0.116 & 1.551 & 0.112 & 13.794 \\
\hline & & 15 & 1.588 & 0.200 & 1.489 & 0.193 & 7.721 \\
\hline & \multirow{4}{*}{35} & 0 & 1.102 & 0.033 & 1.034 & 0.032 & 32.488 \\
\hline & & 5 & 1.571 & 0.059 & 1.474 & 0.057 & 26.053 \\
\hline & & 10 & 1.689 & 0.114 & 1.584 & 0.110 & 14.336 \\
\hline & & 15 & 1.614 & 0.197 & 1.514 & 0.191 & \begin{tabular}{|l|}
7.949 \\
\end{tabular} \\
\hline & \multirow{4}{*}{40} & 0 & 1.132 & 0.032 & 1.062 & 0.031 & 34.481 \\
\hline & & 5 & 1.599 & 0.057 & 1.500 & 0.055 & 27.036 \\
\hline & & 10 & 1.716 & 0.113 & 1.610 & 0.109 & 14.770 \\
\hline & & 15 & 1.636 & 0.196 & 1.534 & 0.189 & 8.116 \\
\hline
\end{tabular}




\begin{tabular}{|c|c|c|c|c|c|c|c|}
\hline $\begin{array}{c}\text { Ride } \\
\text { Height } \\
\text { (h/c) }\end{array}$ & $\begin{array}{c}\text { Velocity } \\
(\mathbf{m} / \mathbf{s})\end{array}$ & $\begin{array}{l}\text { AoA } \\
\text { Deg. }\end{array}$ & $C_{L}$ & $C_{D}$ & $\begin{array}{c}\text { Corrected } \\
\mathrm{C}_{\mathrm{L}}\end{array}$ & $\begin{array}{c}\text { Corrected } \\
\mathrm{C}_{\mathrm{D}}\end{array}$ & $\mathbf{C}_{\mathrm{L}} / \mathbf{C}_{\mathrm{D}}$ \\
\hline \multirow{16}{*}{0.15} & \multirow{4}{*}{25} & 0 & 0.752 & 0.025 & 0.706 & 0.024 & 28.993 \\
\hline & & 5 & 1.478 & 0.046 & 1.387 & 0.044 & 31.310 \\
\hline & & 10 & 1.568 & 0.096 & 1.471 & 0.093 & 15.777 \\
\hline & & 15 & 1.541 & 0.182 & 1.446 & 0.176 & 8.224 \\
\hline & \multirow{4}{*}{30} & 0 & 0.873 & 0.026 & 0.818 & 0.026 & 32.043 \\
\hline & & 5 & 1.553 & 0.046 & 1.457 & 0.045 & \begin{tabular}{|l|}
32.664 \\
\end{tabular} \\
\hline & & 10 & 1.705 & 0.097 & 1.600 & 0.094 & 17.039 \\
\hline & & 15 & 1.609 & 0.180 & 1.509 & 0.174 & 8.652 \\
\hline & \multirow{4}{*}{35} & 0 & 0.894 & 0.025 & 0.838 & 0.024 & 34.263 \\
\hline & & 5 & 1.591 & 0.044 & 1.492 & 0.043 & 34.713 \\
\hline & & 10 & 1.740 & 0.095 & 1.632 & 0.092 & 17.786 \\
\hline & & 15 & 1.631 & 0.178 & 1.530 & 0.172 & \begin{tabular}{|l|}
8.890 \\
\end{tabular} \\
\hline & \multirow{4}{*}{40} & 0 & 0.910 & 0.024 & 0.854 & 0.024 & 36.172 \\
\hline & & 5 & 1.621 & 0.043 & 1.520 & 0.042 & 36.230 \\
\hline & & 10 & 1.772 & 0.094 & 1.662 & 0.091 & 18.356 \\
\hline & & 15 & 1.674 & 0.174 & 1.570 & 0.168 & \begin{tabular}{|l}
9.323 \\
\end{tabular} \\
\hline \multirow{16}{*}{0.2} & \multirow{4}{*}{25} & 0 & 0.661 & 0.022 & 0.620 & 0.021 & 29.278 \\
\hline & & 5 & 1.390 & 0.038 & 1.304 & 0.037 & 35.319 \\
\hline & & 10 & 1.598 & 0.083 & 1.499 & 0.080 & 18.737 \\
\hline & & 15 & 1.544 & 0.168 & 1.448 & 0.162 & \begin{tabular}{|l|}
8.940 \\
\end{tabular} \\
\hline & \multirow{4}{*}{30} & 0 & 0.749 & 0.023 & 0.703 & 0.022 & 32.059 \\
\hline & & 5 & 1.506 & 0.038 & 1.413 & 0.037 & 38.701 \\
\hline & & 10 & 1.758 & 0.082 & 1.649 & 0.079 & 20.882 \\
\hline & & 15 & 1.597 & 0.164 & 1.498 & 0.159 & \begin{tabular}{|l|}
9.435 \\
\end{tabular} \\
\hline & \multirow{4}{*}{35} & 0 & 0.764 & 0.022 & 0.717 & 0.021 & 34.189 \\
\hline & & 5 & 1.531 & 0.036 & 1.436 & 0.035 & 40.961 \\
\hline & & 10 & 1.769 & 0.080 & 1.659 & 0.078 & 21.360 \\
\hline & & 15 & 1.625 & 0.162 & 1.525 & 0.156 & 9.743 \\
\hline & \multirow{4}{*}{40} & 0 & 0.776 & 0.021 & 0.728 & 0.020 & 36.050 \\
\hline & & 5 & 1.555 & 0.035 & 1.458 & 0.034 & 42.968 \\
\hline & & 10 & 1.799 & 0.079 & 1.687 & 0.076 & 22.227 \\
\hline & & 15 & 1.688 & 0.156 & 1.583 & 0.150 & 10.529 \\
\hline \multirow{16}{*}{ ree-driy } & \multirow{4}{*}{25} & 0 & 0.400 & 0.015 & 0.375 & 0.015 & 25.753 \\
\hline & & 5 & 1.054 & 0.021 & 0.989 & 0.020 & 48.903 \\
\hline & & 10 & 1.478 & 0.039 & 1.386 & 0.038 & 36.953 \\
\hline & & 15 & 1.465 & 0.104 & 1.374 & 0.100 & 13.713 \\
\hline & \multirow{4}{*}{30} & 0 & 0.405 & 0.014 & 0.380 & 0.014 & 27.458 \\
\hline & & 5 & 1.063 & 0.020 & 0.997 & 0.019 & 51.212 \\
\hline & & 10 & 1.498 & 0.037 & 1.406 & 0.036 & 39.099 \\
\hline & & 15 & 1.496 & 0.099 & 1.403 & 0.096 & 14.647 \\
\hline & \multirow{4}{*}{35} & 0 & 0.409 & 0.014 & 0.384 & 0.013 & \begin{tabular}{|l|}
28.947 \\
\end{tabular} \\
\hline & & 5 & 1.070 & 0.019 & 1.003 & 0.019 & 53.303 \\
\hline & & 10 & 1.514 & 0.036 & 1.420 & 0.035 & 40.862 \\
\hline & & 15 & 1.536 & 0.094 & 1.441 & 0.091 & 15.804 \\
\hline & \multirow{4}{*}{40} & 0 & 0.412 & 0.013 & 0.386 & 0.013 & 30.320 \\
\hline & & 5 & 1.076 & 0.019 & 1.009 & 0.018 & 55.233 \\
\hline & & 10 & 1.526 & 0.035 & 1.431 & 0.034 & 42.239 \\
\hline & & 15 & 1.564 & 0.091 & 1.467 & 0.088 & 16.654 \\
\hline
\end{tabular}

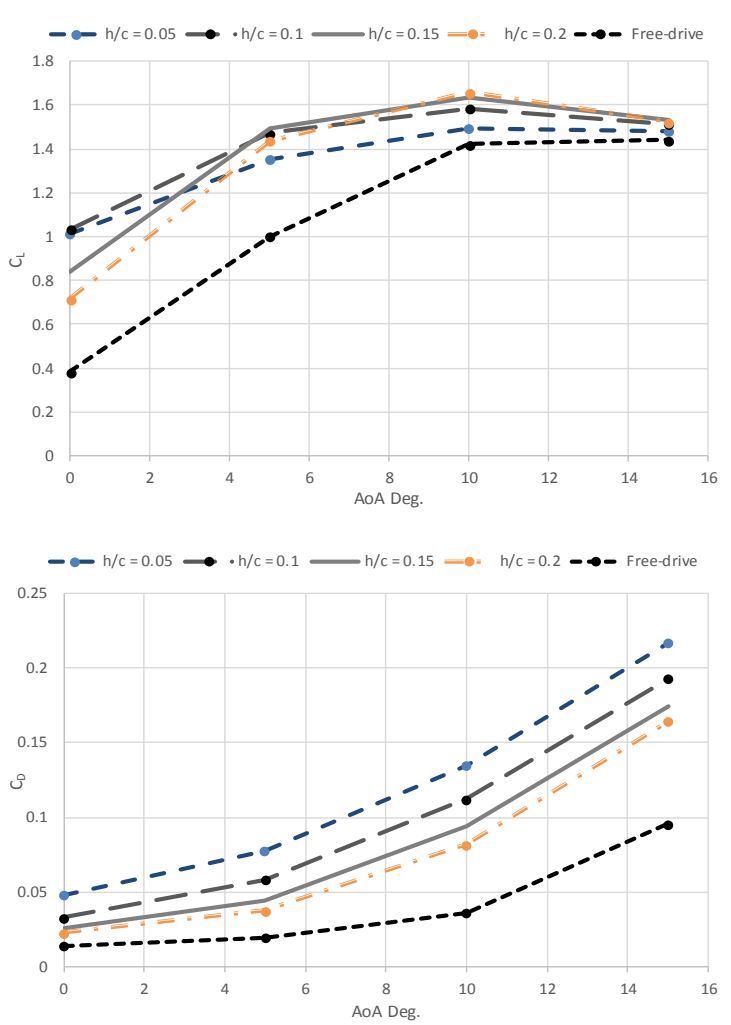

(a): at $25 \mathrm{~m} / \mathrm{s}$ reference velocity

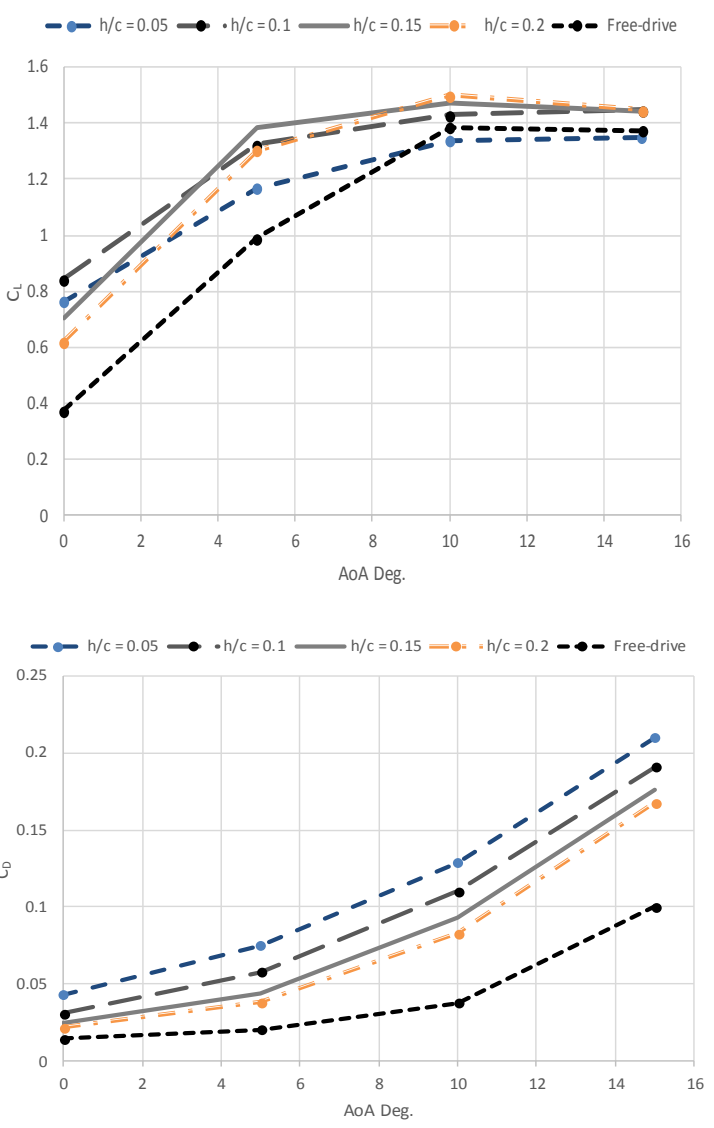

(b): at $30 \mathrm{~m} / \mathrm{s}$ reference velocity 

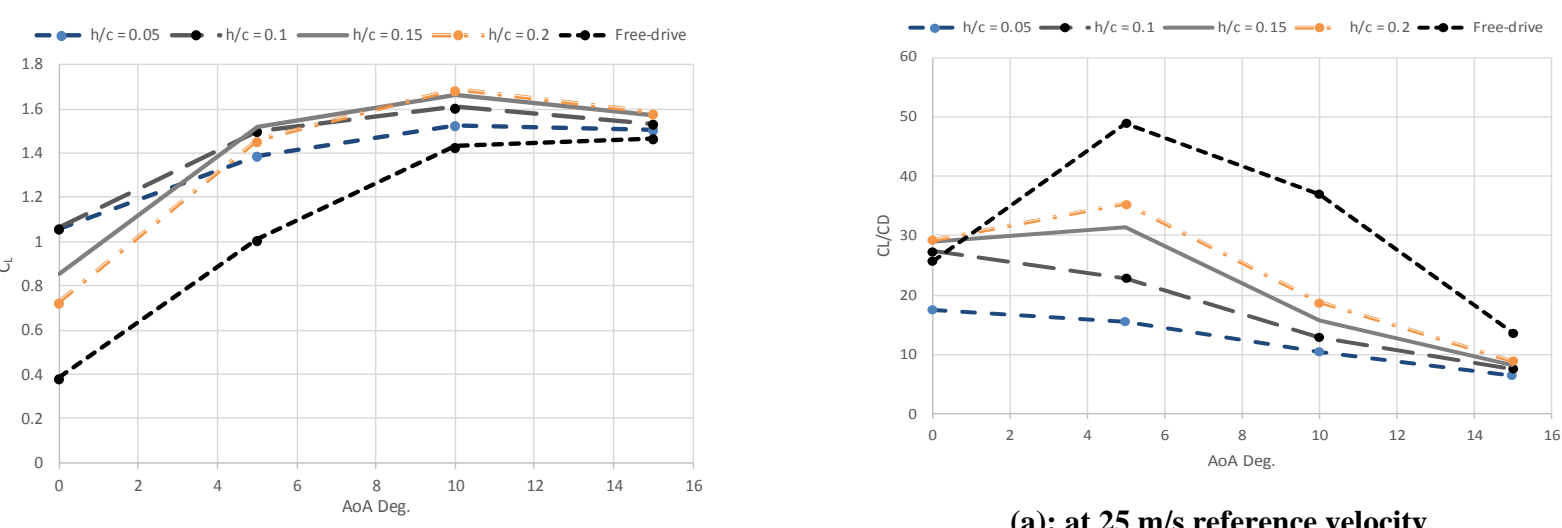

(a): at $25 \mathrm{~m} / \mathrm{s}$ reference velocity
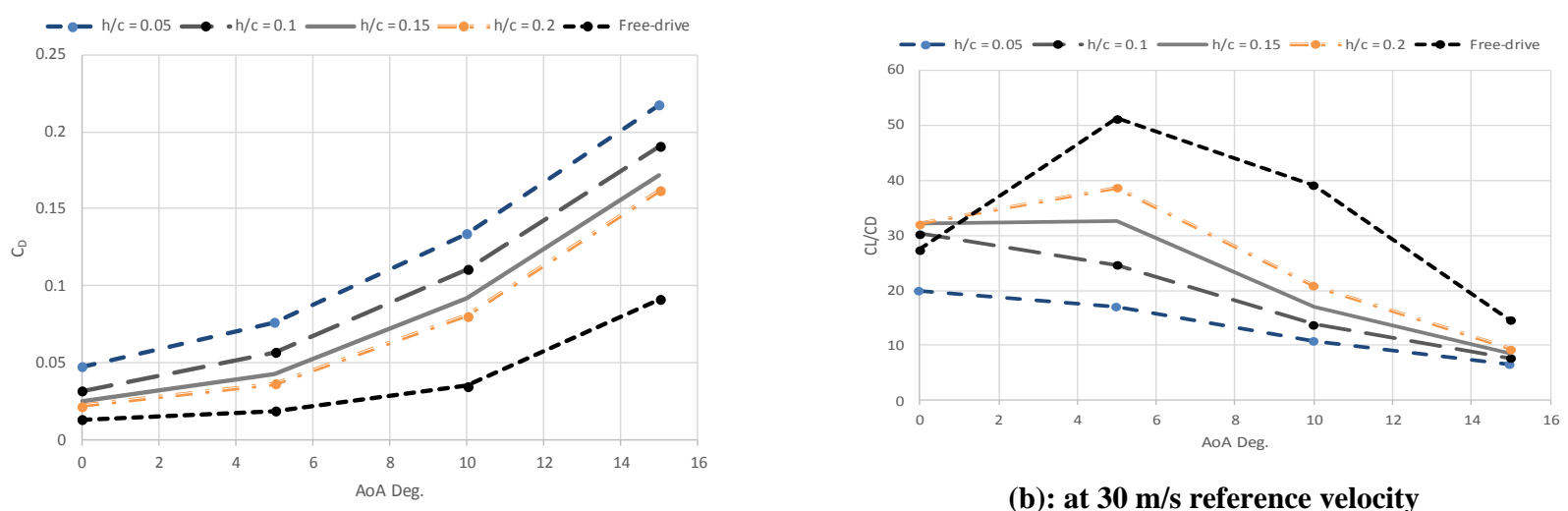

(b): at $30 \mathrm{~m} / \mathrm{s}$ reference velocity

(c): at $35 \mathrm{~m} / \mathrm{s}$ reference velocity
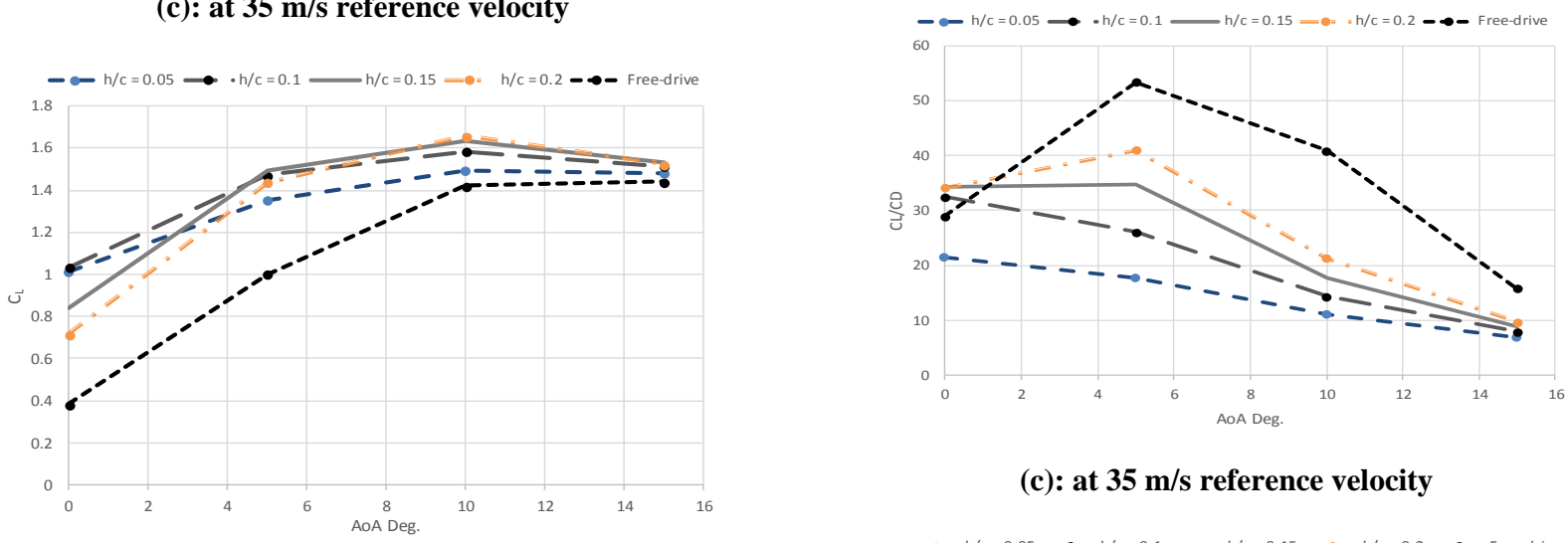

(c): at $35 \mathrm{~m} / \mathrm{s}$ reference velocity

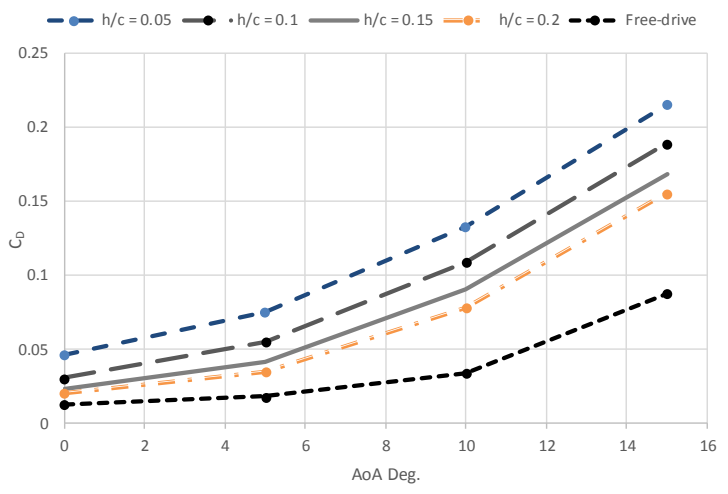

(d): at $40 \mathrm{~m} / \mathrm{s}$ reference velocity

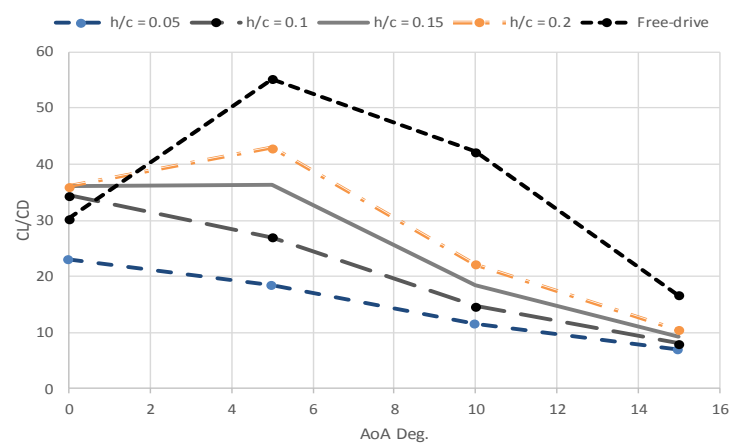

(d): at $40 \mathrm{~m} / \mathrm{s}$ reference velocity

Fig 4: Negative Lift to Drag Coefficients Variation with AoA and Ride Height at Different Speeds

Fig 3: Negative Lift and Drag Coefficients Variation with AoA and Ride Height at Different Speeds 


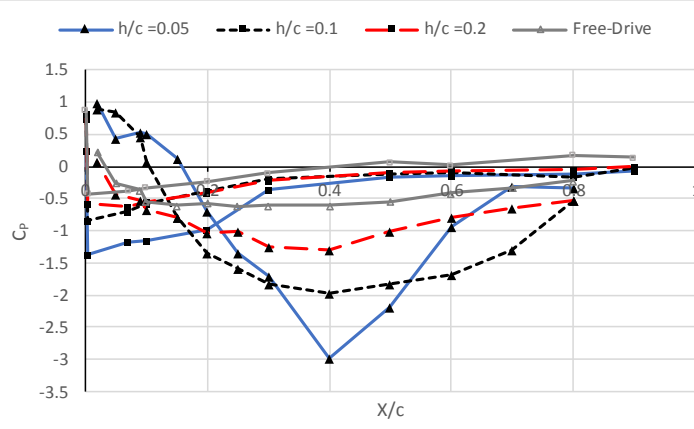

(a): at $0^{\circ}$ reference $A o A$ and $25 \mathrm{~m} / \mathrm{s}$ reference speed

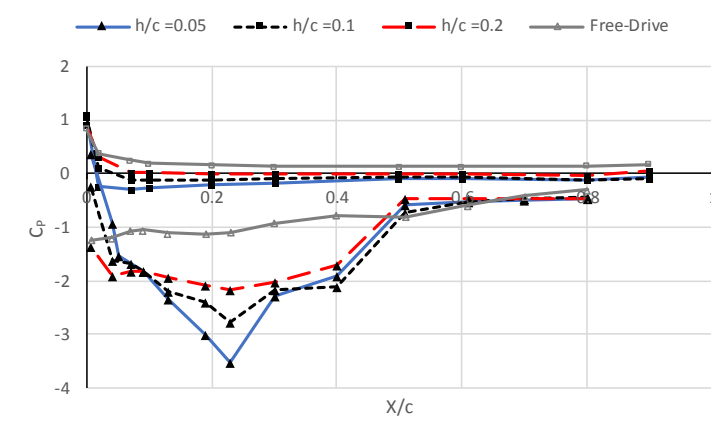

(b): at $5^{\circ}$ reference $A o A$ and $30 \mathrm{~m} / \mathrm{s}$ reference speed

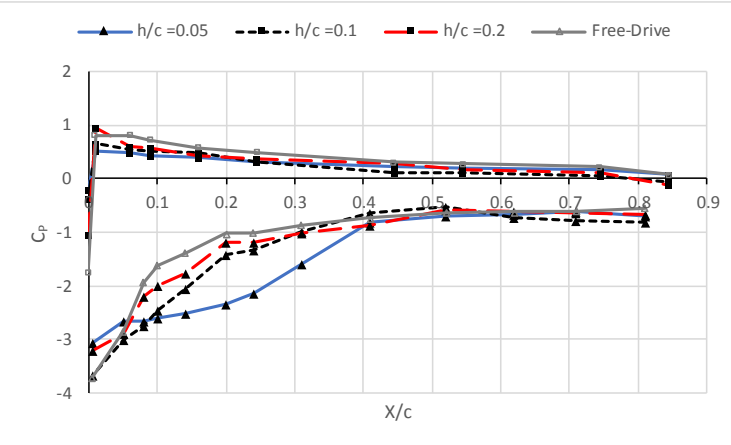

(c): at $15^{\circ}$ reference $A o A$ and $40 \mathrm{~m} / \mathrm{s}$ reference speed

Fig 5: Pressure Coefficient Variation of Lower and Upper Surfaces at Three Set Levels for Different Ride Heights

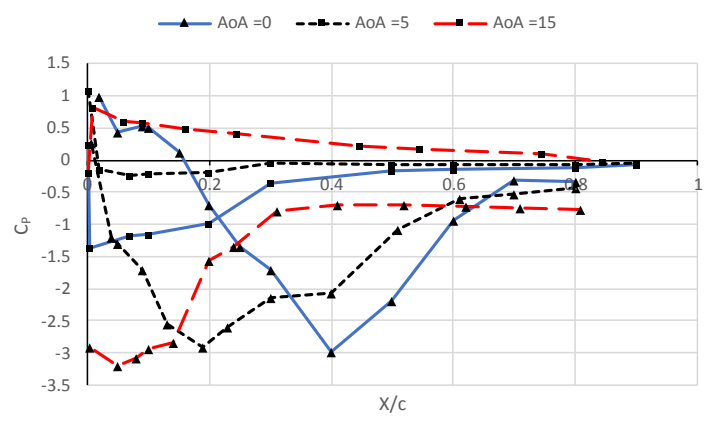

(a): at 0.05 reference $h / c$ and at $25 \mathrm{~m} / \mathrm{s}$ reference speed

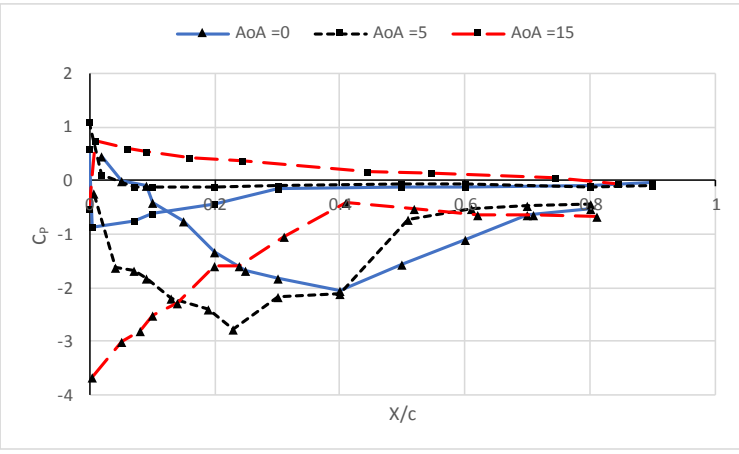

(b): at 0.1 reference $h / c$ and at $30 \mathrm{~m} / \mathrm{s}$ reference speed

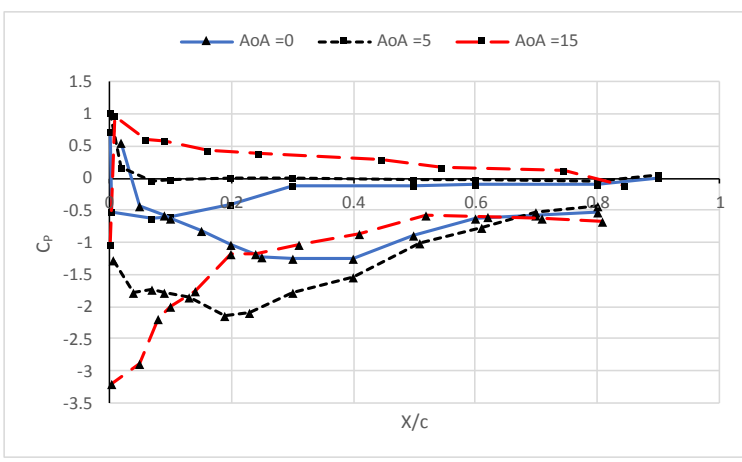

(c): at 0.2 reference $h / c$ and at $40 \mathrm{~m} / \mathrm{s}$ reference speed

Fig 6: Pressure Coefficient Variation of Lower and Upper Surfaces at Three Set Levels for Different Angles of Attack

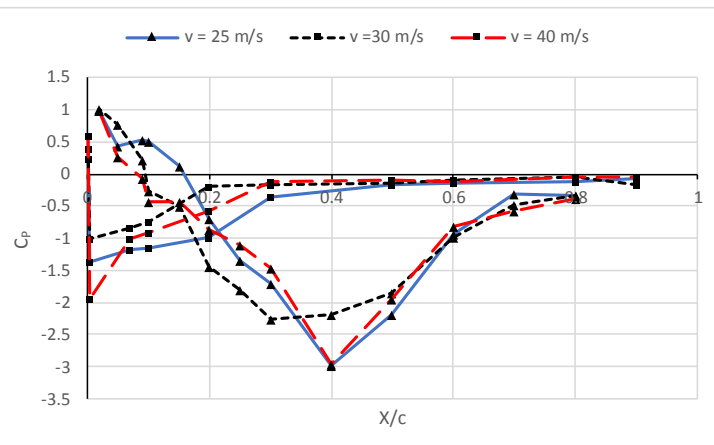

a): at $0.05 \mathrm{c}$ reference $\mathrm{h} / \mathrm{c}$ and at $0^{\circ}$ reference $\mathrm{AoA}$

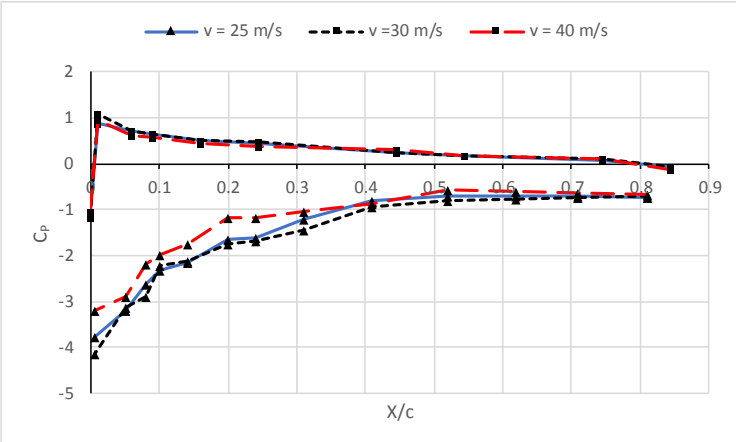

(b): at $0.2 c$ reference ride $h / c$ and at $15^{\circ}$ reference $A o A$

Fig 7: Pressure Coefficient Variation of Lower and Upper Surfaces at Three Set Levels for Different Speeds 


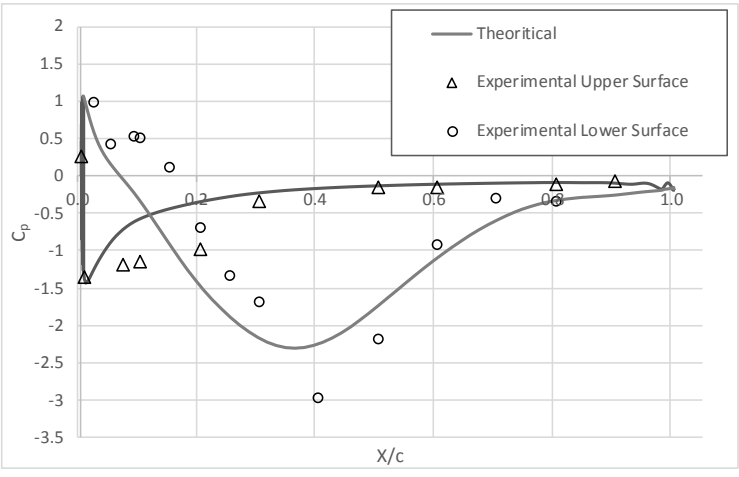

(a): at $\alpha=0^{\circ}, h / c=0.05, v=25 \mathrm{~m} / \mathrm{s}$

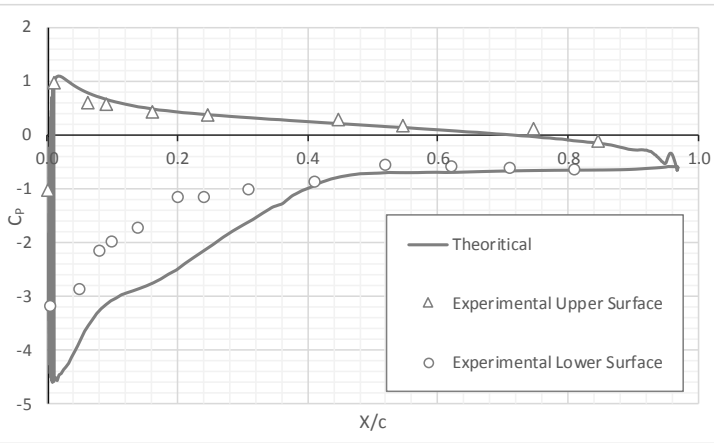

(b): at $\alpha=15^{\circ}, \mathrm{h} / \mathrm{c}=0.2, \mathrm{v}=40 \mathrm{~m} / \mathrm{s}$

Fig 8: Pressure Coefficient Comparison of a Single Clarkysm-il Airfoil with Ground Effects

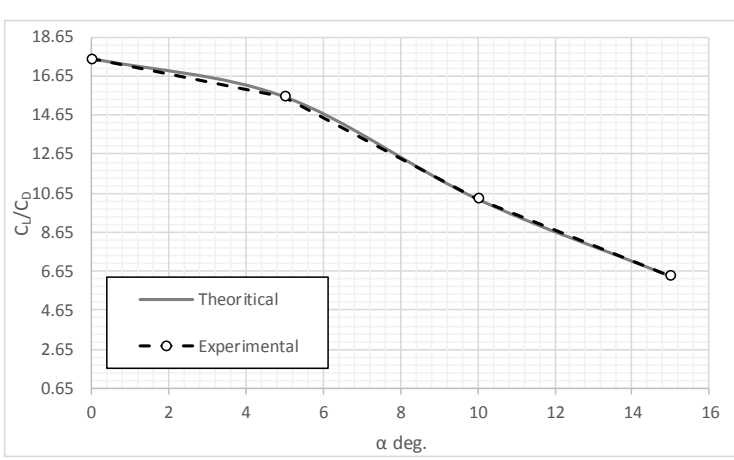

(a): at $h / c=0.05, v=25 \mathrm{~m} / \mathrm{s}$

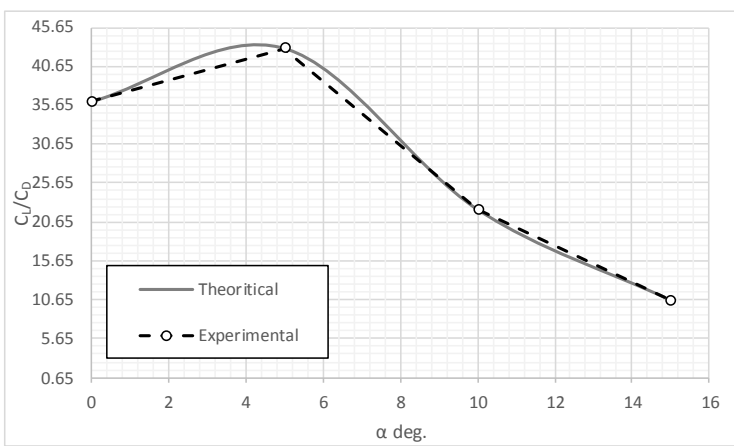

(b): at $\mathrm{h} / \mathrm{c}=0.2, \mathrm{v}=40 \mathrm{~m} / \mathrm{s}$

Fig 9: Negative Lift to Drag Theoretical [16] and Experimental Comparison of a Single Clarkysm-il Airfoil in Ground Effects

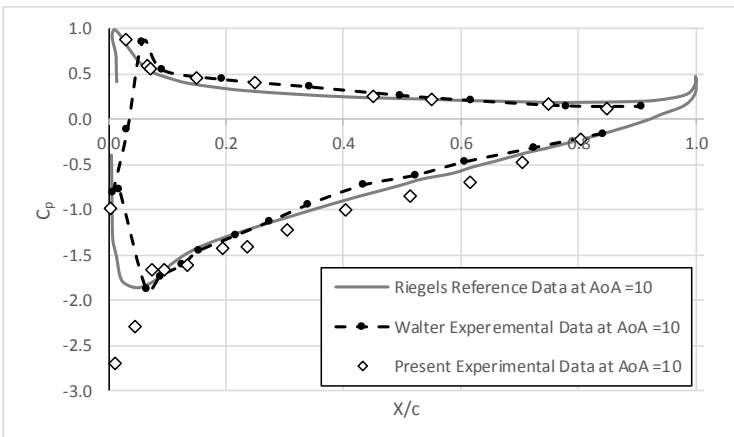

(a): $\operatorname{Re}=7.1 \times 10^{5}$ and Free of Ground

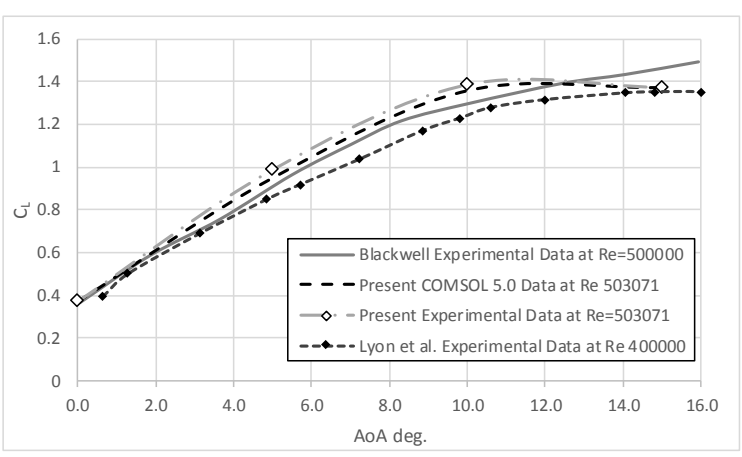

(b): Lift Coefficient with Ground Effects

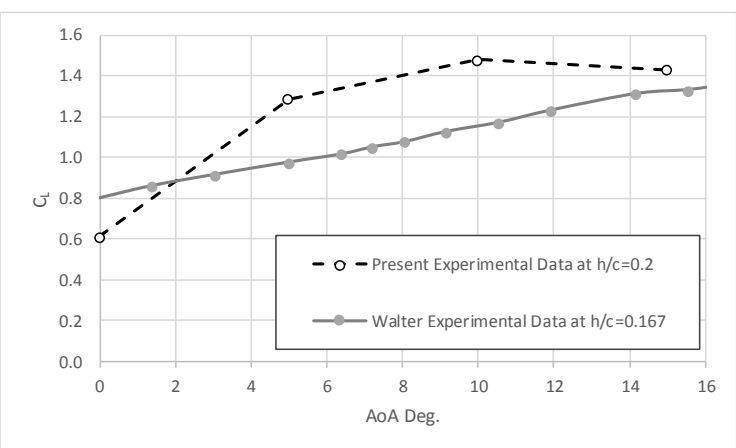

(c): Lift Coefficient with Ground Effects

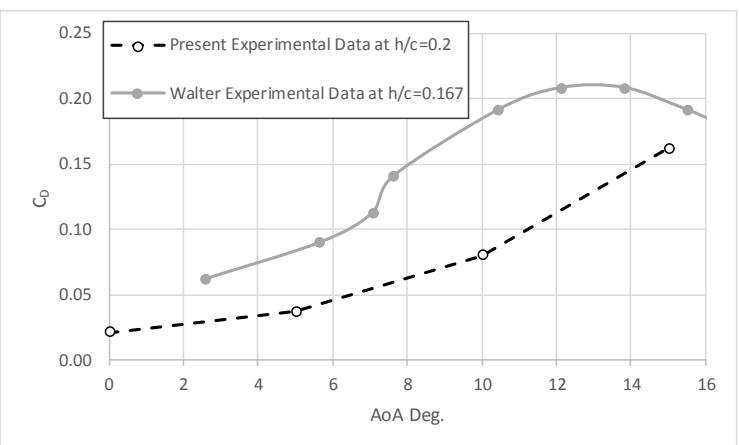

(d): Drag Coefficient with Ground Effects

Fig 10: Theoretical and Experimental Verifications of Pressure Coefficient Distribution for the Upper and Lower Surface of Clarkysm-il airfoil and Aerodynamic Characteristics at $\mathrm{Re}=\mathbf{5 . 1 4 \times 1 0 ^ { 5 }}$

\section{CONCLUSIONS}

Single element inverted airfoil CLARK-Y smoothed is tested at different ground clearances, at different angles of 
attack and at different speeds (Reynolds numbers) through the low-speed wind tunnel experiments and compared with free-drive case.

The present study shows significant effects of angle of attack, free stream velocity and ride height on aerodynamic characteristics, these conclusions can be summarized as follows:

- $\quad$ The negative lift coefficient increased with increasing the angle of attack and with ground proximity except at high angles of attack larger than $10^{\circ}$ and except at ride heights of less than 0.1 due to the force reduction phenomena.

- The drag coefficient increases with increasing the angle of attack and with decreasing the ride height. The minimum drag at the free-drive case.

- The efficiency (lift to drag) increases at high ride heights and generally maximum at $5^{\circ}$ angle of attack.

- Separation of the boundary layer occurred close to the trailing edge of the suction surface, at a higher angles of attack, larger than $10^{\circ}$, and at a moderate ride height.

- The velocity effects were least significance on the aerodynamic characteristics.

- The surface pressure along upper and lower surfaces of the airfoil increases in the ground proximity, for low angles of attack, and with angle of attack increasing.

\section{ACKNOWLEDGMENTS}

The authors would like to thank Dr.Anmar Hamid Ali, a lecturer at the Mech. Engr. Dept., for providing us with unlimited help and support during all phases of the work.

\section{REFERENCES}

[1] Mahon, S. and Zhang, X., "computational analysis of inverted double-element airfoil in ground effect", Journal of fluids engineering, ASME, 128(6):11721180,2005

[2] Cui, E.J. (1998), "Surface effect aero-hydrodynamics and its applications". Sadhana, 23(5), 569-577.

[3] Rozhdestvensky, K.V., (2006) Wing-in ground effect vehicles. Prog. Aerosp. Sci., 42, 211-283.

[4] Dominy, R. G., "Aerodynamics of Grand Prix cars", Proceedings of the Institution of Mechanical Engineers, Part D: Journal of Automobile Engineering, Vol. 206, pp. 267-274, 1992.
[5] Katz, J., "Considerations pertinent to race-car wing design," RAeS. Conference on "Vehicle Aerodynamics", Loughborogh, U.K., pp. 231-237, 1994.

[6] Knowles, K., Donoghue, D. T., and Finnis, M. V., 1994, "A Study of Wings in Ground Effect," Proceedings of the Loughborough University Conference on Vehicle Aerodynamics, Vol. 22, pp. $1-13$.

[7] Jasinski, W. J. and Selig, M. S., "Experimental study of open-wheel race-car front wings", SAE 1998 Transaction-Journal of Passenger Cars, Vol. 107, Section 6, 1999.

[8] Zerihan, J.D.C. and Zhang, X., "Aerodynamics of a single element wing in ground effect," Journal of Aircraft, Vol. 6, 2000, pp. 1058-1064.

[9] Galoul, V. and Barber, T.J., " A Study of an Inverted Wing with Endplates in Ground Effect", abstract p 1, 2007.

[10] Walter, D. J.," Study of Aerofoils at High Angle of Attack, in Ground Effect.", M.Sc. Thesis, School of Aerospace, Mechanical \& Manufacturing Engineering Portfolio of Science, Engineering \& Technology Rmit University, September 2007.

[11] Blackwell, T., "Subsonic Wind Tunnel with Corrections on a Wing with a Clark Y-14 Airfoil", Master's Thesis, San Jose State University, 2011.

[12] Hussain I. Y. and Ali A. H., "Calibration of LowSpeed Wind Tunnel (LSWT) Test Section", Baghdad University Engineering Journal, Dossier No. ME-576, accepted at 22/6/2014.

[13] Moran J., "An Introduction to Theoretical and Computational Aerodynamics", John Wiley and Sons Int., 1984

[14] I. Y. Hussain and M.S. Abood, "Aerodynamic Characteristics of CLARK-Y Smoothed Inverted Wing with Ground Effects," International Journal of Computer Applications (0975 - 8887), vol. 136, no 7, pp. 42-50, 2016.

[15] Riegels, F.W., "Aerodynamic sections", P. 213-214, butterworths, London, (1961).

[16] Lyon, C. A., Broern, A. P., Giguore, P., Gopalarathnam, A. and Selig, M. S., "Summary of Low- Speed Airfoil Data", Vol.3. University of Illinois at Urbana-Champaign, (1995). 